УДК 81

ББК 82

\section{C.A. Eторова}

\section{лингво- \\ СТИЛИСТИЧЕСКИЕ \\ СРЕДСТВА ВЫРАЖЕНИЯ ЭКСПРЕССИВНОСТИ В СПОРТИВНОЙ ПУБЛИЦИСТИКЕ}

Дискурсивное пространство спортивной публицистики обусловливается интенциональностью и характеристиками коммуникативной ситуации, что позволяет его изучать с позиций прагмастиликтики, лингвокультурологии, дискурсивной лингвистики, теории речевого воздействия, социолингвистики. Фокус исследовательского внимания сосредоточивается при этом на выяснении тех факторов, которые обеспечивают коммуникативную эффективность медиатекстов. Определяющая роль среди этих факторов принадлежит элокутивной организации дискурса медиа.

Ключевые слова: Әискурсивное пространство, элокутивные особенности, медиатекст, экспрессивность, target-группа, целеустановка, оценочность.

DOI 10.18522/1995-0640-2020-4-89-96

Егорова Светлана Александровна - аналитик отдела международных проектов и программ, Донской государственный технический университет

Tel: + 7-950-869-49-89

E-mail: s_zinyakova@mail.ru

(C) Егорова C.A., 2020.
Элокутивные особенности спортивного публицистического текста определяются самыми разными коммуникативными установками, которые объединяет воздействие такого текста на возможно более широкого адресата, а цель этого воздействия заключается в максимальном, прагматически заданном информировании.

Прагматика спортивной публицистики как значимого компонента сферы массмедиа осуществляется посредством механизмов реализации стратегической коммуникативной задачи. Современная лингвистика опирается в этой связи на постулат о дуализме медиатекстов: в них используется прямой и опосредованный способы речевого воздействия, представлена социально значимая информация, а речевая структура отражает чередование информативного и воздействующего принципов организации текста.

Безусловно, медиадискурс представляет на сегодня один из наиболее мобильных, непрерывно трансформирующихся видов дискурса, а лингвостилистический анализ медиатекстов, в том числе и принадлежащих к спортивной публицистике, позволяет установить, каковы основные тенденции общественного сознания, их содержательные черты и закономерности.

Дискурсивное пространство массмедиа, представляющее собой систему текстов, становится важной сферой применения новых средств экспрессивности. Конкретизация социальной целеустановки приводит к тому, что инвариантные характеристики текстов 
многообразно преломляются в конкретных репрезентациях, а изучение элокутивной организации спортивной публицистики делает возможным не только выявление когнитивно-дискурсивных механизмов построения высказывания, но и определение коммуникативного эффекта, достигнутого / не достигнутого при применении конкретной организации текста. Изучение коммуникативно-прагматических свойств элокутивных средств спортивной публицистики обусловливает исследовательский интерес к информативным, воздействующим, эстетическим компонентам публицистического дискурса, которые образуют целостный комплекс.

В настоящее время происходит бурное развитие газетно-публицистического дискурса и, соответственно, публицистического стиля как такого функционального стиля, который наиболее востребован в различных жанрах данного дискурса (статья, репортаж, интервью, очерк). Тематический спектр применения публицистического стиля весьма широк (экономика, спорт, религия, образование, новости), что обусловлено востребованностью данного стиля в различных сферах социальных отношений (политика, культура, наука). Экспрессивность данного стиля развивается за счет использования различных пластов лексики, что определяет и расширение оценочного и когнитивного потенциала языка в целом. Большие возможности самовыражения приобретает языковая личность адресанта публицистического дискурса, прежде всего, благодаря эмоционально-оценочным средствам и специальной терминологической лексике.

Сегодняшние массмедиа позволяют наблюдать «рождение» языка современности, одной из основополагающих черт которого является ориентация на адресата, на эффективную коммуникацию. Поэтому с уверенностью можно утверждать, что газетно-публицистический дискурс сосредоточен на нескольких коммуникативных задачах: сообщении последних новостей, на их комментировании и оценке.

Языковая специфика публицистического стиля определяется взаимодействием его главных функций - воздействующей и информативной: первая отвечает за наличие и формирование оценочной лексики, вторая «формирует речевые стандарты, строевую лексику, нейтральный слой словаря, которые необходимы для словесного оформления сообщений» [Кожина, Дускаева, Салимовский, 2011, с. 285]. Как верно отмечает С.И. Бикмуканова, публицистический стиль не реализует эстетическую или контактоустанавливающую функции, но, тем не менее, такие функции присутствуют в газетно-публицистическом дискурсе, однако весьма специфически транслируются с помощью графических средств, что позволяет автору статьи привлечь внимание возможно более широкого круга читателей [Бикмуканова, 2014, с. 3].

Термин публицистический стиль представляется в настоящее время наиболее удачным, поскольку, в отличие от терминологических сочетаний «общественно-политический», «газетный» или «газетно-публицистический» стили, данный термин не фиксирует сферу его при- 
менения слишком узко. Тесная связь термина публицистический стиль с публицистикой, являющейся важной частью литературного процесса, позволяет выявлять не только формальные, но и содержательные особенности публицистических текстов: так, газетно-публицистический дискурс, для которого характерен публицистический стиль, отличается длительным отбором лингвостилистических средств экспрессивности, «которые в полной мере отвечают условиям социального задания, которое выполняет газета» [Бойкова, 2007, с. 151]. Основной задачей периодических изданий является возможно более оперативная трансляция новостей, что отражается в тексте сообщений: они имеют довольно сжатый формат, содержат основные аспекты события, при этом направлены на реализацию эмоционального воздействия на адресата. Поэтому можно с уверенностью говорить о постепенном выдвижении на первый план воздействующей функции, тогда как информационная функция становится второстепенной. Также необходимо отметить, что зачастую адресант сообщения не имеет достаточного количества времени на стилистическую обработку текста, что становится причиной определенных трансформаций публицистического стиля, среди которых наиболее часты употребление разговорной лексики и стандартизация публицистического стиля, см., напр.: [Коньков, 2005]. В тесной связи с этими двумя аспектами можно говорить об осуществлении воздействующей функции в координатах общего стиля, идеологии и тематической направленности конкретного периодического издания («формата», в терминологии журналистики), а также об имплицитности маркеров языковой личности конкретного автора в текстах газетно-публицистического дискурса, поскольку такие тексты подчинены требованиям газетно-журнальной публицистики, а адресант зачастую отражает в них позицию определенного социального слоя, профессионального сообщества или политической партии [Швейцер, 2009, с. 157].

Одной из важных черт публицистического стиля является применение оценочной лексики, которой, как правило, придается заметная эмоциональная окрашенность. Публицистический стиль осуществляет целый ряд коммуникативных задач, среди которых определяющим значением обладают «воздействие на сознание читателей, побуждение к действию, сообщение информации» [Швейцер, 2009, с. 155]. Так, например, уже заголовок аналитической статьи «Счет растет не в пользу бедных», сопровождаемый подзаголовоком «Ежегодный финансовый отчет UEFA, зафиксировал увеличение разрыва между богатыми и всеми остальными» [КоммерсантЂ, 18.01.2018, URL] создает определенный эмоциональный настрой реципиента, поскольку воздействует на один из самых болезненных аспектов жизни современного общества - существование имущественного и социального неравенства. На наш взгляд, такой заголовок, несомненно, реализует одну из главных целей - привлекает внимание адресата, вызывает необходимую реакцию - возмущение существующим положением дел, причем не только в сфере спорта, но и в целом в обществе. Представляется, что реакция адресата 
здесь оказывается как бы двусторонне направленной: с одной стороны, статья помещена в разделе «Спорт» газеты «КоммерсантЬ», поэтому заведомо понятно, что аналитическая статья будет посвящена каким-либо спортивным вопросам; с другой стороны, такой заголовок имеет расширительное толкование, и его семантика распространяется на другие социальные сферы. Также отметим, что само выражение «счет растет» применяется в случае комментирования спортивного состязания, матча в значении 'увеличивается количество набранных очков', однако в данном контексте это лексическое сочетание приобретает и иное значение 'увеличивается количество денет на банковском счете', что в целом демонстрирует переосмысление адресантом известного выражения, благодаря чему воздействие на адресата становится более эффективным.

Интересно также, что эмоциональная окрашенность в спортивной аналитической статье реализуется посредством разноуровневых по своей принадлежности языковых и речевых средств, среди которых приоритет отдан вводным словам и конструкциям. Анализ языкового материала показал, что чем более образованной и эрудированной мыслится целевая аудитория конкретного периодического издания, тем более вероятно, что эмоциональная окрашенность и оценочность будут имплицитны, например: «В среду Союз европейских футбольных ассоциаций представил ежегодный отчет под названием “Ландшафт европейского клубного футбола”. В нем детально анализируется ситуация по итогам 2016 финансового года (по существу, речь идет о том, что произошло в прошлом сезоне, закончившемся летом 2017-го). Этот отчет уже девятый по счету, выпущенный UEFA. Но нынешний по своему значению, возможно, отличается от всех остальных. Во всяком случае, большинство экспертов, изучавших документ, пришли к выводу, что он очень похож на программный для президента UEFA Александра Чеферина, поскольку акцентирует внимание на всех тех проблемах, о которых он говорил, занимая должность руководителя континентального футбола осенью 2016 года, и которые до сих пор остаются нерешенными» [КоммерсантЪ, 18.01.2018, URL]. В приведенном примере выделены курсивом маркеры оценочности и эмоциональной окрашенности, закономерно имплицитные, поскольку адресант не желает навязывать свое отношение к происходящим событиям, однако и не намерен быть абсолютно нейтральным к конкретному анализируемому событию в жизни UEFA. Кроме того, обращает на себя внимание и лексическое сочетание на программный для президента UEFA, которое подчеркивает важность документа, детально проанализированного в данной статье.

Лексика публицистического стиля характеризуется ярко выраженной экспрессивностью и эмоциональностью, что может быть реализовано в газетно-публицистическом дискурсе посредством включения в текст жаргонизмов, арготизмов, просторечных и разговорных речевых элементов. Такие лексические компоненты используются, разумеется, и в других видах дискурса, однако в публицистическом стиле они позво- 
ляют адресанту воссоздать то или иное событие в таком ключе, чтобы иметь возможность оказать влияние на читателя.

Интересно, что лексика, не включаемая в состав литературной, довольно редка для собственно спортивных аналитических статей и обзоров, например: «Объясняя причины роста, авторы отчета во многом повторяют аргументы, которые приводились в аналогичных отчетах за предыдущие годы. Они сводятся к хорошей в целом экономической конъюнктуре в европейском футболе, выливающейся в том числе в новые, гораздо более выгодные, чем истекшие, контракты на продажу медийных прав, а также к позитивной роли самого UEFA. В частности, к внедренной им в начале десятилетия программе финансового fair-play, стимулирующей сокращение расходов и повышение эффективности коммерческой деятельности» [КоммерсантЂ, 18.01.2018, URL]. В приведенном примере, представляющем собой фрагмент аналитической статьи, адресатом которой должен, в соответствии с форматом издания, выступать читатель, знакомый с ситуацией в UEFA и в мировом футболе в целом, владеющий основами экономических знаний, лексические средства представляют собой компоненты экономического и спортивного институционального дискурсов и нацелены на транслирование важной информации.

Просторечные и разговорные элементы могут появляться в тех фрагментах текстов, относимых к спортивному газетно-публицистическому дискурсу, которые характеризуют речь самих субъектов спорта (спортсменов, их тренеров, болельщиков, представителей спортивной медицины и пр.), например: «Оценивая свои спортивные результаты, Никита Крюков сам себе поставил твердую пятерку. "Звание чемпиона Олимпиады - это уже пять, а в рукаве еще и три золота чемпионатов мира, - отметил он. - Есть небольшой осадок от сочинской Олимпиады. Это был траур, полгода держало это серебро. Я получил не то, на что настраивался. Были разные мысли, слезы, которые я никому не показывал, но мне удалось пройти через это. Друзья потом подарили мне пластиковую копию золотой медали, и с того момента я перестроился” $[$ КоммерсантЂ, 08.04.2019, URL]. В приведенном фрагменте разговорные и просторечные элементы (выделены курсивом) позволяют воссоздать живую речь интервьюируемого. Кроме того, разумеется, такие элементы усиливают эмоциональную окрашенность текста не только за счет самого освещаемого в нем события, но и благодаря эксплицированному отношению спортсмена к описываемым аспектам его пути в спорте. Так, употребление устоявшегося в педагогическом дискурсе, однако не приобретшего пока статуса закрепленного в сфере литературного языка высказывания поставил твердую пятерку свидетельствует, по всей видимости, и об ориентации адресанта спортивного дискурса на широкую читательскую аудиторию, всем представителям которой понятен смысл этого высказывания, и об особенностях психологии спортсмена, который постоянно ориентируется исключительно на одобрение собственных достижений, как и отличники в отечественных средних школах и ву- 
зах. Интересно также употребление в речи спортсмена устойчивого выражения, пришедшего из речи карточных шулеров а в рукаве еще и три золота. Данный случай не имеет однозначного истолкования, тем более, что спортивные достижения Никиты Крюкова никто не оспаривает и он может гордиться ими открыто. Однако необходимо подчеркнуть, что современные антидопинговые скандалы заставляют спортсменов, видимо, беспокоиться и о своих прошлых победах и их легитимности. Также весьма показательным можно считать и реализацию в этом фрагменте речевого штампа в микроконтексте $Е с т ь$ небольшой осадок от сочинской Олимпиады. На наш взгляд, речевое клише осадок от..., применяемое в речи, обладает достаточной степенью эмоциональной окрашенности для отражения внутреннего мира продуцента дискурса, как и разговорные полгода держало это серебро, перестроился.

Как правило, спортивный газетно-публицистический дискурс ориентирован на информирование широких слоев населения, а целевой аудиторией становится некий усредненный реципиент. Тем не менее, необходимо здесь особо подчеркнуть, что спортивная публицистика может иметь и вполне конкретную target-группу: болельщики, фанаты, читатели, обладающие весьма широкими познаниями в сфере конкретного вида спорта. Так, в следующем фрагменте заметен весьма значительный объем сведений, которые имеют большую объяснительную силу и позволяют такой целевой аудитории не только владеть всей информацией о предстоящем спортивном событии, но и определенным образом прогнозировать его дальнейшее развитие: «Первый Fed Cup Finals по замыслу руководства ITF состоится ровно через год, во второй половине апреля. Четыре сборные - финалисты нынешнего розыгрыша, одна обладательница wild card и команда-хозяйка - попадут в “финальную дюжину” напрямую, а остальные участницы определятся по итогам восьми февральских матчей квалификационного раунда. Вот за попадание в этот раунд и поспорят сейчас россиянки с итальянками, хотя формально встреча в Москве называется матчем за место во 2-й Мировой группе» [КоммерсантЂ, 19.04.2019, URL].

В том же ключе можно расценивать и прагматику следующего текстового фрагмента аналитической публицистической статьи: «Первой ракеткой мира по итогам года в пятый раз $(2008,2010,2013,2017,2019)$ стал испанец Рафаэль Надаль. Это стало ясно после того, как в Лондоне на итоговом турнире Ассоциации теннисистов-профессионалов (АТР) Nitto ATP Finals серб Новак Джокович после поражения на групповом этапе от швейцарца Роджера Федерера не смог выйти в полуфинал. Таким образом, Рафаэль Надаль обновил сразу несколько своих рекордов. B частности, с того момента как он дебютировал в ранге первой ракетки мира по итогам года, прошло цельх одиннадцать лет» [Коммерсант Ђ, 16.11.2019, URL]. Необходимо особо выделить в данном макроконтексте наличие имен собственных (разумеется, окруженных дополнительной сетью как национально-специфичных, так и индивидуальных ассоциаций) - Рафаэль, Надаль, Новак, Джокович, Роджер Федерер, а также 
наименования Ассощиащии теннисистов-профессионалов (АТР). Кроме того, важной прагматической составляющей данного микроконтекста следует также считать вводные слова (в частности), обстоятельств $($ сразу) и атрибутивов (цель $)$, имеющих оценочный компонент семантики в составе конкретного высказывания. Таким образом, даже читатель, невнимательно следящий за достижениями Рафаэля Надаля, должен понять, что он стал первой ракеткой мира по праву, обновив свой же рекорд.

Также особо отметим наличие в координатах публицистического стиля клише, которые позволяют ввести в сообщение авторскую оценку и отразить в нем общую идеологическую позицию издания. Так, авторская оценка является значимым прагматическим компонентом в следующем контексте: «Это означало, что Рафаэль Надаль, который находился не в лучшей форме, довольно быстро уступил Александру Звереву и чудом одолел Даниила Медведева, отыграв матчбол при счете 1:5 в третьем сете, в любом случае останется на первом месте. И это абсолютно закономерно. Одержав, как и Джокович, две победы на чемпионатах Большого шлема и турнирах категории Masters 1000, испанеи, в целом выступал на главных состязаниях стабильнее» [КоммерсантЬ, 16.11.2019, URL]. В приведенном макроконтексте адресант указывает на небольшие просчеты и неудачи Рафаэля Надаля (который находился не в лучшей форме, довольно быстро уступил), а также случайные победы теннисиста (чудом одолел), однако выражает совершенно однозначную положительную оценку спортивных достижений Надаля и - имплицитно - убежденность в его превосходстве над другими спортсменами (в любом случае останется на первом месте, и это абсолютно закономерно, испанец, в целом выступал на главных состязаниях стабильнее).

Поскольку спорт представляет собой сложный и противоречивый социальный феномен, занимающий важное место в жизни социума, можно говорить о спортивном газетно-публицистическом дискурсе как об особом виде коммуникации, который реализует, как и спорт в целом, целый комплекс общественных потребностей. Спортивным текстам свойственны информативность, логичность, точность и объективность, ясность и понятность. Разумеется, конкретные тексты будут обладать данными особенностями в разной степени, однако во всех таких текстах будут использоваться такие языковые средства, которые будут способствовать удовлетворению потребностей спортивной коммуникации.

\section{Литература}

Бикмуканова С.И. Публицистический стиль и его функционирование // ScienceTime. URL: http://cyberleninka.ru/article/n/publitsisticheskiy-stil-i-egofunktsionirovanie (дата обращения 15.04.2020).

Бойкова Н. Г. (2007). Современная газетная публицистика: Проблемы стиля. Л.: Изд-во Ленинградского ун-та. 287 с.

Кожина М.Н., Дускаева Л.Р., Салимовский В.А. (2011). Стилистика русского языка. М.: Флинта: Наука. 464 с. 
Коньков В.И. (2005). Речевая структура газетного текста. СПб.: Изд-во С-Петербургского ун-та. $151 \mathrm{c}$.

Тертыиный А.А. (2006). Жанры периодической печати: учеб. пособие: 3-е изд., испр. и доп. М.: Аспект Пресс. 319 с.

Швейцер А.Д. (2009). Контрастивная стилистика: Газетно-публицистический стиль в русском и английском языках / под ред. В.Н. Ярцевой: 2-е изд. М.: Книжный дом «ЛИБРОКОМ». 256 с.

\section{Источники языкового материала}

Спорт-КоммерсантЪ. URL: https://www.kommersant.ru/rubric/9 (дата обрщения 24.03.2020).

\section{References}

Bikmukanova S.I. Publicistic style and its functioning. ScienceTime. Available at: http://cyberleninka.ru/article/n/publitsisticheskiy-stil-i-ego-funktsionirovanie (accessed 15.04.2020) (In Russian).

Boykova N.G. (2007). Modern newospaper journalism: Problems of style. Leingrad.: Publishing house of the Leningrad University, 287 p. (In Russian).

Kozhina M.N., Duskaeva L.R., Salimovsky V.A. (2011). Russian language stylistics. Moscow: Flinta: Nauka, 464 p. (In Russian).

Kon'kov V.I. (2005). Speech structure of newospaper text. Sankt-Petersburg, 151 p. (In Russian).

Schweitzer A.D. (2009). Contrasting stylistic: Newospaper and journalistic style in English and Russian. Under the editorship of V.N. Yartseva. 2-nd edition. Moscow, Publishing house «LIBROKOM», 256 p. (In Russian).

Tertychny A.A. (2006). Genres of periodicals: study guide. 3-rd edition., corrected and supplemented. Moscow, Aspect Press, 319 p. (In Russian).

Language material sources

Sport-Kommersant. Available at: https://www.kommersant.ru/rubric/9 (acessed 24.03.2020).

Svetlana A. Egorova (Rostov-on-Don, Russian Federation) Journalism

Linguistic Means of Expressiveness Manifestation in Sports

The discoursespace of sportsjournalismis determined by theintentionality and characteristics of the communicative situation, which allow it to be studied from the standpoint of pragmastylistics, cultural linguistics, discursive linguistics, the theory of speech influence, and sociolinguistics. However, the focus of research attention is fixated on clarification of those factors that provide the communicative effectiveness of media texts. The decisive role among these factors belongs to the elocutional organization of the media discourse.

Key words: discourse space, elocutional peculiarities, media text, expressivity, target-group, objective, evaluativity.

Svetlana A. Egorova - post-graduate student. Southern Federal University. Analyst of international projects and program department of Don state technical university. Phont: +7-950-869-49-89; e-mail: s_zinyakova@ mail.ru 